\title{
Prevalence and impact of osteoarthritis and osteoporosis on health-related quality of life among active subjects
}

\author{
Véronique Rabenda ${ }^{1}$, Christelle Manette ${ }^{1}$, Régine Lemmens ${ }^{2}$, Anne-Marie Mariani ${ }^{2}$, Nicole Struvay ${ }^{2}$, \\ and Jean-Yves Reginster ${ }^{1}$ \\ ${ }^{1}$ WHO Collaborating Center for Public Health Aspects of Osteoarticular Disorders, Department of Public \\ Health, Epidemiology and Health Economics, University of Liège, ${ }^{2}$ Department of Population, Liège City \\ Council, Liège, Belgium
}

ABSTRACT. Background and aims: To assess the prevalence and impact of osteoarthritis (OA) and osteoporosis (OP) on health-related quality of life (HRQOL) among active subjects employed in the public workforce in Belgium. Methods: A cohort of 3440 subjects employed by the Liège City Council was prospectively followed for 6 months. The employees were asked to fill in a monthly log in a health record book, of data regarding their healthcare consumption due to $O A$ and $O P$. HRQOL was assessed using the Medical Outcomes Study Short Form-36 (SF-36). Results: 1811 subjects (52.6\%) filled in at least one questionnaire. The mean duration of follow-up was 3.46 months. The self-reported prevalence of $O A$ and $O P$ at entry to the study were respectively $34.1 \%$ and $5.3 \%$. $3.6 \%$ of subjects reported suffering from both $O A$ and $O P$. Subjects with $O A$ and both $O A$ and $O P$ had significantly lower scores on all SF-36 dimensions compared with normal subjects, reflecting a worse HRQOL. The $O P$ group had significantly lower mean scores for physical functioning and pain compared with controls. Subjects with both $O A$ and $O P$ had significantly lower values for physical functioning, physical role and pain when compared with the $O A$ and $O P$ groups. Conclusions: The results of this survey of a large sample of active subjects show that self-reported osteoarthritis and osteoporosis are common in the workplace. Both diseases have a major impact on health-related quality of life compared with that of people without self-reported musculoskeletal diseases.

(Aging Clin Exp Res 2007; 19: 55-60)

${ }^{\circ} 2007$, Editrice Kurtis

\section{INTRODUCTION}

The continous increase in life expectancy over the last century has meant that osteoarthritis (OA) and osteoporosis (OP) have become major health concerns woridwide, brought to the fore by their significant medi$\mathrm{cal}$, social and psychological consequences on healthrelated quality of life (HRQOL).

$\mathrm{OA}$, which is characterized by loss of joint cartilage, leading to pain and loss of function; primarily at the knee and hip, is the most common rheumatic disorder. It is one of the leading causes of physical disability in Westem industrialized countries, and is associated with significant health and welfare costs $(1,2)$. Worldwide estimates are that $9.6 \%$ of men and $18 \%$ of women aged 60 years and over have symptomatic OA (3). In Western populations, as many as one-third of adults aged 25-75 years have evidence of radiographic OA. Although it does not reduce life expectancy, OA affects multiple dimensions of patients' quality of life, has a significant impact on emotional wellbeing and relationships with friends and family, and also affects body image and self-esteem (4). OA is responsible for losses in work and social activities and for difficulties in performing self-care tasks (5).

$O P$ is characterized by low bone mass and microarchitectural deterioration of bone tissue, with a consequent increase in bone fragility and susceptibility to fracture. Based on the operational definition used by the World Health Organization, $30 \%$ of postmenopausal white women in the USA are estimated to have OP in at least one skeletal site. The general prevalence of OP rises from $5 \%$ among women and $2.4 \%$ among men aged 50 years, to respectively $50 \%$ and $20 \%$ at 85 years of age (6). The most common clinical complications of OP are fractures of the spine, forearm and hip. Approximately 1.5 million fractures per

Key words: Osteoarthritis, osteoporosis, prevalence, quality of life, workplace.

Correspondence: V. Rabenda, Msc, Department of Public Health, Epidemiology and Health Economics, CHU, Bât. B23, 4000 Liège, Belgium. E-mail: veronique.rabenda@ulg.ac.be

Received February 9, 2006; accepted in revised form April 4, 2006. 
year are attributed to $\mathrm{OP}$. One in three women and one in eight men aged 50 years and older will experience an OP-related fracture in their lifetime (7). It adversely affects quality of life by causing pain. reducing physical functioning and mobility. and affecting the activities of daily living. Depression and social isolation often result (8).

The impact of OP and OA on all social categories of the population and their prevalence increases with age. It is well established that $\mathrm{OP}$ and $\mathrm{OA}$ appear at an advanced age. Nevertheless, a significant number of younger people who are economically active may also suffer. While numerous studies have addressed the impact of $\mathrm{OP}$ and $O A$ and their treatment on quality of life among elderly patients, the prevalence and impact on HRQOL of such disorders in the workplace are mostly unknown.

On the basis of a large sample of active subjects employed in the public workforce, the purpose of this study was to assess the prevalence of self-reported osteoarthritis and osteoporosis, and to present data on health-related quality of life for these two musculoskeletal disorders.

\section{METHODS}

This study is an ancillary protocol to a prospective survey, designed with the primary objective of evaluating the direct and indirect costs attributable to $\mathrm{OA}$ and $\mathrm{OP}$ among a cohort of 3440 subjects employed by Liège City Council, followed over a period of six months.

From January to June 2004, all City Council staff were given a monthly health record book, in which they were asked to keep a prospective log of data regarding their healthcare consumption (contact with health professionals, medical examinations, drugs consumption, etc.) attributable to $\mathrm{OA}$ and/or OP. A great deal of information on demographic (age, gender, level of education, current marital status) and socio-economic (professional status, category of incomes) characteristics was also collected through the survey. To assess comorbidity, we used a 23-item list of comorbid conditions and inquired whether the symptom/condition has been present during the previous 6 months. Subjects were asked to indicate the presence or absence of $\mathrm{OA}^{\prime}$ and OP. For subjects affected by $O A$ and/or $O P$, information about diagnosis, duration of disease, contacts with general practioners or specialists, and treatment taken specifically for $\mathrm{OA}$ and/or $\mathrm{OP}$ during the past six months were also collected during the 6 -month study. To optimize study quality and collect a maximum of data, we set up a reminder procedure. At the start of each month, an appropriate reminder letter was sent to employees who had failed to send in their completed questionnaires within the timeframe.

The protocol of this study was approved by the Ethics Committee of the School of Medicine, University of Liège.

In order to check the representativity of our sample, we compared the age, gender and professional status of both participants and non-responders. There are nine professional categories within the Liège City Council which include several occupations. Since the effective size of most of them was small. we decided to gather them into 3 categories: administrative. manual, and others. We also checked if our sample was representative of the active Belgian population (2003 data: National Institute of Statistics) in terms of age and gender. Since the professional categories were specific to the City Council, it was not possible to compare these data with those available for the active Belgian population.

Health-related quality of life was assessed using the Medical Outcomes Study Short Form-36 item health status survey (SF-36) at baseline. This questionnaire was only administered in the first month (January 2004) of the study period. The term "inclusion" in the present paper means the moment of enrolment of subjects in the survey.

The SF-36 is a generic HR-QOL instrument, consisting of 36 items which measure eight dimensions of health status as reported by patients. Four dimensions refer to physical health: limitations in physical functioning due to health; limitations in usual role activities due to physical health; bodily pain; and perceptions of health in general. Four dimensions refer to mental health: vitality (energy and fatigue); limitations in social activities due to physical or emotional health; limitations in usual role activities due to personal or emotional problems; and general mental health (psychological distress and well-being) $(9,10)$. These dimensions are scored from 0 to 100 , lower scores indicating lower levels of HR-QOL. One of the greatest advantages of the SF-36 is its consistently high levels of reliability (test-retest, intemal consistency) and validity (content, concurrent, criterion, construct, predictive) $(10,11)$. The SF-36 has been broadly applied and validated in measuring health outcomes in both various languages (including French) $(12,13)$ and conditions (including OP and $\mathrm{OA}$ ) (14-17).

\section{Statistic analysis}

Subjects' characteristics were recorded using means and standard deviation (SD) or percentages. Groups were compared by sociodemographic characteristic and comorbidity using the Chi-square test for qualitative variables, Student's $t$-test, and analysis of variance (ANOVA) for quantitative variables.

Because the prevalence of $\mathrm{OA}$ and $\mathrm{OP}$ and the HRQOL are influenced by age and sex, multiple linear regression was used to compare the mean score differences while adjusting for the effects of age and sex. This was carried out by analysis in which each of the 8 mean scores of the SF-36 was separately included in models as dependent variables, and age, sex, number of comorbidities and the presence of each disease were included as independent variables. Age and number of comorbidities were included as continuous variables, and sex and the disease in question as binary categorical 
Table 1 - Comparison of age. gender and professional status between responders and non-responders. and between sample of responders and active Belgian population.

\begin{tabular}{|c|c|c|c|}
\hline$\underset{\text { (n }}{\mathrm{Re}}$ & $\begin{array}{l}\text { Responders } \\
(n=1811)\end{array}$ & $\begin{array}{l}\text { Non-responders } \\
(n=1629)\end{array}$ & $\begin{array}{c}\text { Active Belgian } \\
\text { population } \\
(\mathrm{n}=4070355)\end{array}$ \\
\hline $\begin{array}{l}\text { Gender }(\%) \\
\text { Men } \\
\text { Women }\end{array}$ & $\begin{array}{l}42.6 \\
57.4\end{array}$ & $\begin{array}{l}49.8^{\circ} \\
50.2^{\circ}\end{array}$ & $\begin{array}{l}56.9^{\circ 5} \\
43.1^{\circ 0}\end{array}$ \\
\hline $\begin{array}{l}\text { Age group (\%) } \\
18-25 \\
26-35 \\
36-45 \\
46-55 \\
56-65\end{array}$ & $\begin{array}{r}2.3 \\
16.7 \\
22.7 \\
40.9 \\
17.4\end{array}$ & $\begin{array}{r}3.2 \\
15.1 \\
21.3 \\
41.5 \\
18.9\end{array}$ & $\begin{array}{r}7.5^{\text {no }} \\
27.6^{\circ 0} \\
32.1^{\circ 0} \\
25.1^{\circ 0} \\
7.7^{-00}\end{array}$ \\
\hline $\begin{array}{l}\text { Professional status (\%) } \\
\text { Administrative staff } \\
\text { Non-admnistrative staff } \\
\text { Others }\end{array}$ & ff $\begin{array}{r}32.4 \\
43.3 \\
24.3\end{array}$ & $\begin{array}{l}23.1^{\circ} \\
61.3^{\circ} \\
15.6^{\circ}\end{array}$ & $\dot{-}$ \\
\hline
\end{tabular}

variables. A statistical significance level of $p<0.05$ was used in all statistical tests.

\section{RESULTS}

Of the 3440 subjects employed by the Liège City Council in January 2004, 1811 filled in at least one questionnaire $(52.6 \%)$. The mean duration of follow-up was 3.46 months. Responders had a mean age of 45.9 $( \pm 9.8)$ (us $46.3\{ \pm 10\}$ for non-responders; $p=0.22$ ) and in- cluded more women $(57.4 \%)$ compared with non-responders $(50.2 \%)(p<0.05)$ (Table 1). There was a significant difference in professional status between participants and non-responders. Among responders. the number of subjects with administrative tasks $(32.4 \%$ ) was significantly higher compared with non-responders (23.1\%), whereas fewer manual workers responded $(43.3 \%$ us $61.3 \%)$. We also observed statistically significant differences in terms of age and sex between our sample and the active Belgian population (Table 1). Responders were significantly older and included a larger proportion of women $(57.4 \%)$ compared with the overall active Belgian population (43.1\%).

The self-reported prevalence of OA and OP at entry to the study were respectively $34.1 \%$ and $5.3 \%$. $3.6 \%$ of the active subjects reported suffering from both $\mathrm{OA}$ and $\mathrm{OP}$. When the results were standardized by age and sex to the active Belgian population, the prevalence of $\mathrm{OA}$ and OP were respectively $20.9 \%$ and $2.5 \%$.

The mean age of the OA $(50.7 \pm 6.6), \mathrm{OP}(51.8 \pm 5.7)$ and $\mathrm{OA}-\mathrm{OP}$ groups $(53.1 \pm 6.3$ ) was significantly higher compared with the group without $\mathrm{OA}$ or $\mathrm{OP}$ $(43.1 \pm 10.2)$ (Table 2). The female-to-male ratio was significantly higher in OA (1.5), OP (6.3) and OA-OP groups (5.6) compared with the group without musculoskeletal disorders (1.2). Subjects who suffered from OA $(2.4 \pm 1.9)$ and from both $\mathrm{OA}$ and $\mathrm{OP}(2.9 \pm 2)$ reported a significantly higher mean number of comorbidities $(p<0.05)$ than those with OP $(1.5 \pm 1.8)$ and healthy subjects $(1.3 \pm 1.5)$.

Table 2 - Demographic characteristics.

\begin{tabular}{|c|c|c|c|c|}
\hline & $\underset{(n=1165)}{\text { Control group }}$ & $\underset{(n=551)}{\text { OA group }}$ & $\underset{(n=29)}{\text { OP group }}$ & $\begin{array}{c}\text { OA-OP group } \\
(n=66)\end{array}$ \\
\hline Age (mean $\pm S D$ ) & $43.1( \pm 10.2)$ & $50.7( \pm 6.6)$ & $51.8( \pm 5.7)$ & $53.1( \pm 6.3)$ \\
\hline $\begin{array}{l}\text { Gender (\%) } \\
\text { Men } \\
\text { Women }\end{array}$ & $\begin{array}{l}46 \\
54\end{array}$ & $\begin{array}{l}40.4 \\
59.6\end{array}$ & $\begin{array}{l}13.8 \\
86.2\end{array}$ & $\begin{array}{l}15.2 \\
84.9\end{array}$ \\
\hline Comorbidity (mean $\pm \mathrm{SD}$ ) & $1.3( \pm 1.5)$ & $2.4( \pm 1.9)$ & $1.5( \pm 1.8)$ & $2.9( \pm 2)$ \\
\hline $\begin{array}{l}\text { Marital status (\%) } \\
\text { Married } \\
\text { Divorced } \\
\text { Widowed } \\
\text { Single }\end{array}$ & $\begin{array}{l}47.3 \\
20.8 \\
1.9 \\
30\end{array}$ & $\begin{array}{c}58.2 \\
24.6 \\
3 \\
14.2 \\
\end{array}$ & $\begin{array}{r}50 \\
27.3 \\
13.6 \\
9.1\end{array}$ & $\begin{array}{r}55.1 \\
26.5 \\
4.1 \\
14.3\end{array}$ \\
\hline $\begin{array}{l}\text { Education level (\%) } \\
\text { Primary } \\
\text { Lower secondary } \\
\text { Higher secondary } \\
\text { University }\end{array}$ & $\begin{array}{r}7 \\
28.7 \\
34.9 \\
29.4\end{array}$ & $\begin{array}{r}9.7 \\
28.4 \\
36.5 \\
25.4 \\
\end{array}$ & $\begin{array}{l}4.8 \\
19 \\
28.6 \\
47.6\end{array}$ & $\begin{array}{r}14.6 \\
33.3 \\
43.8 \\
8.3\end{array}$ \\
\hline $\begin{array}{l}\text { Professional status (\%) } \\
\text { Administrative staff } \\
\text { Non-administrative staff } \\
\text { Others }\end{array}$ & $\begin{array}{l}29.9 \\
44.4 \\
25.7\end{array}$ & $\begin{array}{l}36.2 \\
42.4 \\
21.4\end{array}$ & $\begin{array}{l}41.4 \\
17.2 \\
41.4\end{array}$ & $\begin{array}{l}37.9 \\
42.4 \\
19.7\end{array}$ \\
\hline
\end{tabular}


Subjects reported that diagnoses of $O A$ and $O P$ had been made bu health professionals in respectively $96.3 \%$ and $100 \%$ of the cases. Diagnosis of OA was confirmed by radiography in $80 \%$ of subjects. $89 \%$ of the diagnoses of OP were confirmed by bone densitometry. For most of the $\mathrm{OA}(35 \%)$ and $O P$ subjects $(61 \%)$, the mean duration of the disease was between 1 and 5 years. Respectively $43 \%$ and $31 \%$ of $\mathrm{OA}$ subjects were undergoing treatment by a general practitioner or a specialist at enrolment. More than half of OP patients were undergoing treatment at enrolment by a general practitioner $(55 \%)$ or a specialist (55\%). During the previous six months, treatment for OA or OP had been taken in $47 \%$ of OA subjects and $69 \%$ of OP subjects, respectively.

Figure 1 shows the values of the various dimensions of the SF-36 in the OA, OP and OA-OP groups, and in the group without musculoskeletal disorders (controls). Values for all subscales of the SF-36 were significantly lower $(p<0.05)$ for subjects with OA and OA-OP compared with controls. The OP group had lower mean scores in all the dimensions of the SF-36 compared with healthy subjects, but these differences not reach statistical significance, except for physical functioning and pain. The mean score for pain was significantly lower for OA compared with OP. Subjects who suffered from both $O A$ and $O P$ had significantly lower values for physical functioning, physical role and pain when compared with the other groups.

\section{DISCUSSION}

The results of this study show the high prevalence of self-reported $O A$ and $O P$ among active subjects. $O A$ and OP were more commonly reported bu women than by men. and the prevalence of these disorders increased with age. which is characteristic of an osteoarthritic and osteoporotic population. However, about one-third of the study sample reported $O A$. and the self-reported prevalence of OP was 5\%, which is high compared with self-reported prevalences of OA and OP in other population-based surveys. Lawrence et al., on the basis of data from the 1971-1975 NHANES, estimated that $12.1 \%$ of Americans aged between 25 and 74 have clinical signs and symptoms of $\mathrm{OA}(18)$. In an Australian study, OP was reported to be present in $4: 8 \%$ of women and $1.4 \%$ of men (19). In Belgium, according to the results of the Health Interview Survey (HIS), the prevalence of self-reported OA and OP were respectively, $11.7 \%$ and $3.3 \%$ in 2001 . The difference between the results in these two studies may be due to differences in the study sample. It should be borne in mind that our sample was not randomly representative of the Beigian population. Responders included a majority of women (57.4\%) and most of the subjects were aged 46 or over. Since OA and $\mathrm{OP}$ are more frequent in women and older people, it is not surprising that the self-reported prevalence of $\mathrm{OA}$ and OP was higher in our study than in the Belgian HIS and in other surveys. The data-set generated by our study relates only to subjects' self-perceived health. Diagnoses reported were spontaneously mentioned, and were not confirmed by any objective method. They probably include diagnoses made by a general practioner without any measurements, a specialist on the basis of bone mineral density, or by the individuals themselves,

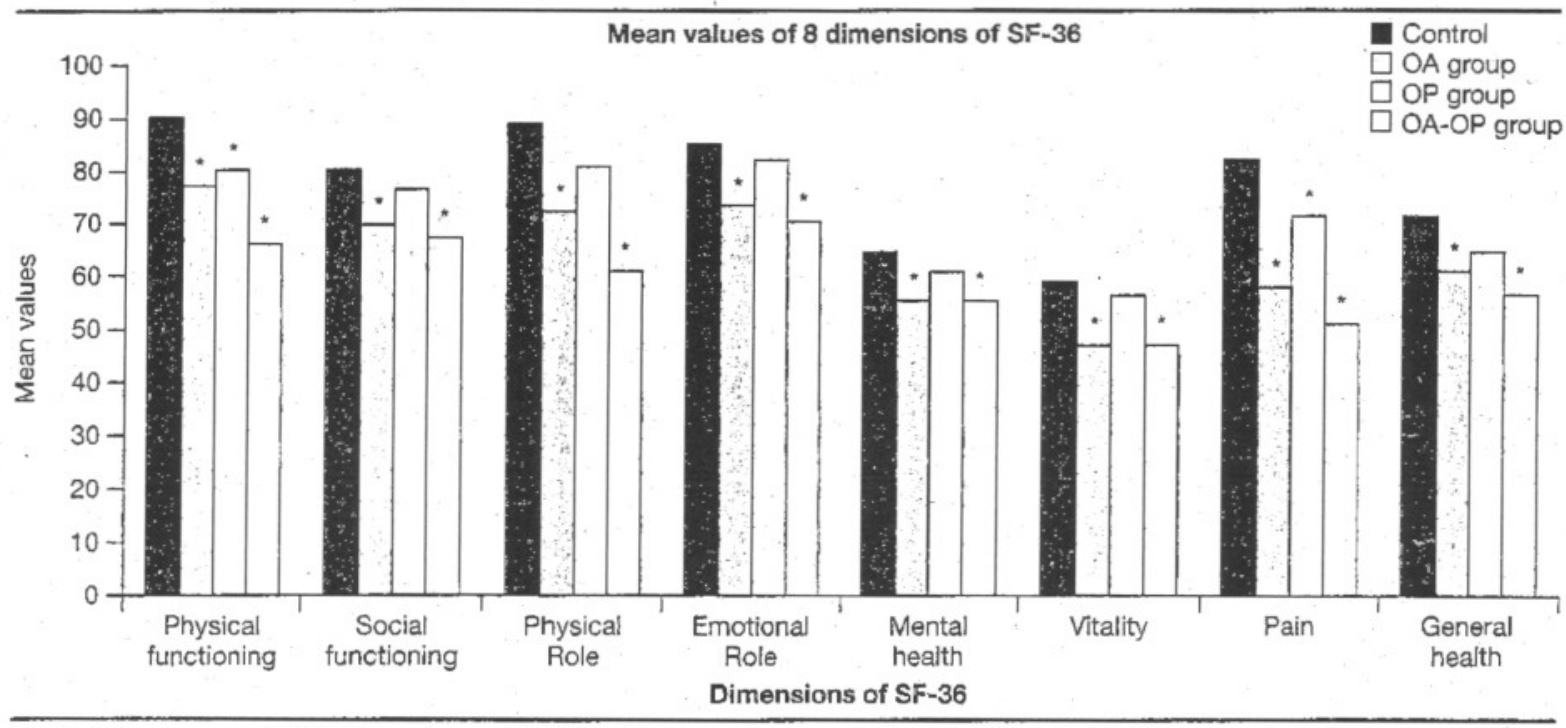

Fig. 1 - Mean scores of eight dimensions of SF-36 in the control group, and in OA, OP, and OA-OP groups. "P<0.05: statistically sig. nificant difference between controls and $O A, O P$, and $O A-O P$ groups, adjusted for age, gender and comorbidities. 
sometimes mistakenly. It is also well established that the prevalence of diseases from self-reporting is generally much higher than that estimated from physical examinations or registrations (20).

Compared with individuals without any of the target musculoskeletal diseases, and after controlling for other factors that may interfere with the HRQOL, OA and OP were found to have a clearly detrimental effect on the HRQOL of the affected subjects, typically in the areas of pain, physical functioning, and role limitation due to physical heaith problems. These results are consistent with previously reported outcomes. Briggs et al. showed that patients with OA had a lower HRQOL compared with healthy subjects, particularly in the domains of physical health status (bodily pain, physical functioning, physical role) (21). This is also in agreement with a study based on the Sickness Impact profile quality of life measure, which reported a significant limitation in overall function in OA patients and highlighted physical limitations as the main differences between $O A$ patients and controls (22). In our OP patients, all dimensions of the SF-36 were lower compared with those of healthy subjects, but only the dimensions which referred to physical functioning and bodily pain reached statistical significance. Our findings are consistent with those obtained by other researchers investigating quality of life in OP patients using a variety of measures. Fractures are a serious consequence of the disease, which has a very significant adverse effect on quality of life, persisting for some time after the fracture has healed. According to a Canadian Multicentre Osteoporosis Study, participants who had sustained osteoporotic fractures at any time in the past had lower quality of life scores compared with individuals who had never sustained a fracture, and this difference was greatest when measuring physical function (23).

Remarkably, although OA and OP are physical conditions, the mental health dimension was among the lowest scores. A similar affirmation has already been reported, and is consistent with the fact that $O A$ and OP are associated with symptoms of anxiety and depression $(4,8)$. Even among women with no known prior fractures, a diagnosis of OP may have deleterious psychological effects, because of their fear of future fractures, or because they feel it is necessary to make adaptations in their lifestlye to prevent falls and fractures. Our data reinforce the fact that musculoskeletal disorders have a major impact on the psychological condition of the people affected.

The HRQOL scores for subjects with both OA and OP were worse than those with only OA or OP. However, patients who suffered from both reported a similar HRQOL profile with respect to patients with only OA or OP. This confirms the results of a cross-sectional Dutch study which reported a worse quality of life in people with musculoskeletal disorders than in the general population. typically in physical dimensions of the SF-36. with greater decreases with the co-existence of more than one musculoskeletal disorder (24). The study also concluded that $O A$ and $O P$ form part of diseases associated with the worst QOL patterns.

Limitations in our data should be taken into account when interpreting them. First, the reliability of self-reporting of diseases by questionnaire has some drawbacks which may affect the accuracy of prevalence figures for $O A$ and $O P$. As mentioned above, it is possible that diseases were reported without having been diagnosed by a physician. However, a large proportion of the subjects reported that the diagnoses of OA $(96.3 \%)$ and OP $(100 \%)$ had been made by health professionals. It is also possible that subjects failed to report disorders, misunderstood diagnoses, were unwilling to report them, or reported false ones. However, our questionnaire included two specific items about the confirmation of the diagnosis by radiography or bone densitometry. In most cases, subjects reported that disorders had been confirmed by an objective diagnostic tool. We should also note that patients who reported OA or OP may be those who had symptoms and painful $\mathrm{OA}$ or $\mathrm{OP}$ and, that, consequently this fact may bias the results of self-reported prevalence and those of HRQOL. In the case of osteoporosis, despite the availability of expert guidelines on diagnosis and treatment, it is unanimously recognized that this condition remains underdiagnosed and undertreated. The major reason for underdiagnosis is that the most common osteoporotic fractures, vertebral fractures, are asymptomatic and therefore go unrecognized by both patients and physicians. In the present study, it is probable that some subjects with asymptomatic osteoporosis did not know that they suffered from this condition and, consequently, did not report it and were not included in the osteoporosis group. It is also probable that these patients, with an asymptomatic disease, reported better HRQOL. The same may be said for subjects suffering from osteoarthritis.

Another limitation to our study, which may explain the high prevalence of $\mathrm{OA}$ and $\mathrm{OP}$, is the rate of non-responses. It is important to note that no financial compensation was offered; only a reminder procedure was set up (so that respondents remained motivated throughout the reporting period), in order to optimize study quality and to collect a maximum of data. While this study was planned in order to evaluate direct and indirect costs, and the impact on HRQOL induced by OA and OP, subjects who suffered from these disorders may have been more willing to participate than subjects without these disorders. This hypothesis may also explain the lack of representativity of our study sample with respect to the total population employed by Liège City Council and the overall active Belgian population. As mentioned above, our sample of responders included a majority of women, and $\mathrm{OA}$ and 
$O P$ are more frequent among women. This is consistent with the self-reported prevalence of $O A$ and $O P$ by gender reported in our study. Additionally, participants were older than the average active Belgian population. It is important to note that the people employed by Liège City Council are generally appointed permanently. Moreover, assuming that people who suffer from OA or OP are more favourable toward participation, it is not surprising that our sample included older people, since the prevalence of these disorders increases with age.

Despite these limitations, the ciata provide a realistic representation of these chronic conditions in the workplace, given the magnitude of the data-set, the validity of the results, and the concordance with results from the literature. Indeed, as expected, $\mathrm{OA}$ and $\mathrm{OP}$ tend to increase in prevalence with age, and are more often reported by women. This is further enhanced by the observation that the mean score difference varies in a predictable manner among groups; $\mathrm{OA}$ and $\mathrm{OP}$ patients scored lowest in all dimensions of the SF-36, physical limitations being the main difference between affected and heaithy subjects.

In conclusion, the results of this survey of a large sample of active subjects show that self-reported OA and OP are common in the workplace. Decreased HRQOL is an important consequence which should be considered when evaluating the burden of these disorders. $\mathrm{OA}$ and OP have a significant impact on the HRQOL of active subjects, especially in the domains of physical health status. Our findings highlight the importance of undertaking more research on the burden induced by these disorders in the workplace, as well as increasing employers' awareness of the importance for their employees to prevent and detect problems which could threaten their health and professional lives.

\section{ACKNOWLEDGEMENTS}

This work was supported by an unrestricted educational grant from Roche and GlaxoSmithKline.

\section{REFERENCES}

1. Badley EM. The effect of osteoarthritis on disability and health care use in Canada. J Rheumatol 1995; 43 (Suppl): 19-22.

2. Reginster JY. The prevalence and burden of arthritis. Rheumatology (Oxford) 2002; 41 (Supp1): 3-6.

3. Murray CJL, Lopez AD. The global burden of disease. A comprehensive assessment of mortality and disability from diseases, injuries, and risk factors in 1990 and projected to 2020. Cambridge (MA): Harvard School of Public Health on behalf of the World Health Organization and The World Bank 1996.

4. Carr AJ. Beyond disability: measuring the social and personai consequences of osteoarthritis. Osteoarthritis Cartilage 1999; 7: $230-8$.

5. Gabriel SE, Crowson CS, Campion ME, O'Fallon WM. Indirect and nonmedical costs among people with rheumatoid arthritis and osteoarthritis compared with nonarthritic controls. J Rheumatol 1997; $24: 43-8$.
6. Woolf $\mathrm{AD}$. Pfleger $\mathrm{B}$. Burden of major musculoskeletal conditions Bull World Health Organ 2003: 81: 646-56.

7. Riggs BL. Melton LJ. The worldwide problem of osteoporosis: insights afforted by epidemiology. Bone 1995: 17 (5 Suppl): 505S-11S.

8. Martin AR, Sornay-Rendu E. Chandler JM, Duboeuf F, Giman CJ, Delmas PD. The impact of osteoporosis on quality of life: the OFELY cohort. Bone 2002: 31: 32-6.

9. Ware JE Jr, Sherbourne CD. The MOS 36-item short-form heaith survey (SF-36): I. Concepiual framework and itern selection. Med Care 1992: 30: 473-83.

10. Ware JE Jr. The SF-36 Health Survey. In Spitker B, ed. Quality of Life and Pharmacoeconomics in Clinical Trials. 2nd ed. Philadelphia, PA: Lippincott-Raven Publishers, 1996: 337-45.

11. McHoney CA, Ware JE Jr, Lu JF, Sherboume CD. The MOS 36item Short-Form Health Survey (SF-36): III. Tests of data quality, scaling assumptions, and reliability across diverse patient groups. Med Care 1994; 32: 40-66.

12. Ravazi D, Gandek B. Testing Dutch and French translations of the SF-36 Health Survey among Belgian angina patients. J Clin Epidemiol 1998; 51: 975-81.

13. Leplege A, Ecosse E, Verdier A, Perneger TV. The French SF-36 Health Survey: translation, cultural adaptation and preliminary psychometric evaluation. J Clin Epidemiol 1998; 51: 1013-23.

14. Lips $\mathrm{P}$, Cooper $C$, Agnusdei $D$, et al. Quality of life in patients with vertebral fractures: validation of the Quality of Life Questionnaire of the European Foundation for Osteoporosis (QUALEFFO). Working Party for Quality of Life of the European Foundation for Osteoporosis. Osteoporos Int 1999: 10: 15060.

15. Lydick E, Zimmerman SI, Yawn B, et al. Development and validation of a discriminative quality of life questionnaire for osteoporosis (the OPTQoL). J Bone Miner Res 1997; 12: 456-63.

16. Osteoporosis Quality of Life Study Group. Measuring quality of life in women with osteoporosis. Osteoporos Int 1997; 7: 478-87.

17. Hawker G, Melfi C, Paul J, Green R, Bombardier C. Comparison of a generic (SF-36) and a disease specific (WOMAC) instrument in the measurement of outcomes after knee replacement surgery. J Rheumatol 1995; 22: 1193-6.

18. Lawrence RC, Helmick CG, Amett FC, et at. Estimates of the prevalence of arthritis and selected musculoskeletal disorders in the United States. Arthritis Rheurn 1998; 41: 778-99.

19. Phillipov G, Phillips PJ, Leach G, Taylor AW. Public perceptions and self-reported prevalence of osteoporosis in South Australia. Osteoporos Int 1998; 8: 552-6.

20. Heliövaara M, Aromaa A, Klaukka T, Knekt P, Joukamaa M, Impivaara O. Reliability and validity of interview data on chronic diseases. The Mini-Finland Health Survey. J Clin Epidemiol 1993; 46: 181-91.

21. Briggs A, Scott E, Steele K. Impact of osteoarthritis and analgesic treatment on quality of life of an elderly population. Ann Pharmacotherapy 1999; 33: 1154-59.

22. de Bock GH, Kaptein AA, Touw-Otten F, Mulder JD. Health-related quality of life in patients with osteoarthritis in a family practice setting. Arthritis Care Res 1995; 8: 88-93.

23. Adachi JD, loannidis G, Pickard L, et al. The association between osteoporotic fractures and health-related quality of life as measured by the Health Utilities Index in the Canadian Multicentre Osteoporosis Study (CaMos). Osteoporos Int 2003; 14: 895-904.

24. Picavet HS, Hoeymans N. Health related quality of life in multiple musculoskeletal diseases: SF-36 and EQ-5D in the DMC3 study. Ann Rheum Dis 2004; 63: 723-29. 